\title{
Introducción: ¿Qué podría ser queer y qué es lo que queer podría ser?
}

https://doi.org/10.51897/interalia/IDTQ8580

Este número heterogéneo de InterAlia procura hacer más amplio el significado de queer desde unas posiciones inesperadas. Por un lado, incluye dos traducciones al español de sendos ensayos magistrales de Lee Edelman y David M. Halperin y, por el otro, indaga en lo que tiene de queer la figura del fumador, la música creada con un rebanador de huevo, el adulto que rehúsa renegar de su niñez, el pino parlante que se inventa un cuento melodramático ambientado en la República de Weimar y, finalmente, Patricia Nell Warren, la escritora nacida en Montana (EE. UU.), que aprendió el ucraniano -la lengua de su marido inmigrante- lo suficiente como para llegar a ser reconocida como poeta en Ucrania, que a continuación salió del armario como lesbiana y que acabó publicando el primer bestseller norteamericano sobre hombres gais. Este número de InterAlia se ocupa asimismo de la condición y de las perspectivas de los estudios queer en diferentes lugares, pero también de la mercantilización de las identidades queer como consecuencia de facilitar la información sobre los pronombres de género preferidos, así como otros datos personales, a los actores de la economía de la información global. Por último, este número plantea la cuestión de la aparente falta de un espacio común para quienes se identifican como queers y quienes no comparten más que la singularidad de su deseo. Lxs autorxs de este número se preguntan qué puede ser queer tanto en general como política, filosófica y estéticamente.

Recomendamos también la entrevista original con Heather Love, quien reflexiona sobre un amplio abanico de temas, incluido el problema de la institucionalización de los estudios queer. Por una parte, Love comenta su difícil relación con el mundo académico, afectada por su sensibilidad a las desigualdades de clase y las derivadas de la geografía, y, por otra, subraya la importancia de las alentadoras relaciones horizontales y transgeneracionales fomentadas por las universidades.

El presente volumen da cabida a cuatro excelentes artículos de investigación de Settimo Fiorenzo Palermo (musicología), Zooey Sophia Pook (teoría de la comunicación), Mateusz Świetlicki (estudios literarios) y Luiz Valle Junior (filosofía). El texto que constituye una verdadera rareza literaria es el relato de Liliana Piskorska, quien recurre a la convención del cuento folklórico típico del Romanticismo polaco para dar forma y sentido a fragmentos de materiales de archivo sobre una mujer trans que vivió en la Alemania de antes de la Segunda Guerra Mundial. La pieza sirvió como base de una performance realizada en uno de los parques municipales de la ciudad de Wrocław, en Polonia, constituyendo no solo un homenaje a un ícono queer olvidado sino también un comentario sobre la homofobia actual en Polonia, donde el deseo queer y la no conformidad de género se etiquetan como "ideología". 
Todos los textos originales, salvo uno, están redactados en inglés. El artículo sobre Patricia Nell Warren había sido escrito para el público lector polaco con la intención de acercarle la figura de esa escritora americana, en su momento muy popular, que vino a forjar su identidad queer por medio de sus vínculos con la Europa del Este. Después de haber publicado en 2017 un número especial con la mayoría de los textos en castellano, hemos incluido dos importantes ensayos teóricos traducidos al español, con vistas a mantener el contacto con nuestrxs lectorxs de España y América Latina. 